\title{
Successful Management of a Life-threatening Endotracheal Bleed with Angiographic Stenting
}

\author{
Manju Mary Joseph ${ }^{1}$, Rohit Benjamin ${ }^{2}$, Aswin Padmanabhan ${ }^{3}$, Deepti Bal ${ }^{4}$, Shalini Nair ${ }^{5}$
}

\begin{abstract}
Several operative and postoperative complications have been reported after tracheostomy, including fatal hemorrhage from erosion of a major vessel. We present here a case of hemorrhage after a surgical tracheostomy. This case is being reported on account of the unusual etiology of the hemorrhage and associated high fatality rates. All concerned need to be aware of this complication and its emergency management. Keywords: Endovascular interventions, Innominate artery, Pseudoaneurysm, Trachea arterial fistula, Tracheostomy.

Indian Journal of Critical Care Medicine (2020): 10.5005/jp-journals-10071-23366
\end{abstract}

\section{INTRODUCTION}

Hemorrhage is one of the feared complications after tracheostomy, and fortunately it is rare. In 1879 , Korte ${ }^{1}$ reported the first patient in whom a tracheostomy was complicated by erosion of a major vessel with resultant fatal hemorrhage. The innominate artery is the vessel most commonly involved; other sources of hemorrhage include the carotid artery, thyroid arteries, aortic arch, and innominate vein. ${ }^{2}$ The incidence of tracheoarterial fistula varies from $0.6 \%$ to $0.79 \% .^{3}$ We present here a patient who developed aneurysm of the brachiocephalic artery. We report the multimodal emergent maneuvers undertaken to control bleed, which helped the patient survive the life-threatening catastrophe.

\section{Case Description}

A 41-year-old lady with acute necrotizing encephalitis involving thalamus and secondary cortical venous thrombosis underwent surgical tracheostomy for long-term ventilatory support. The patient had various medical problems including urinary tract infection and a past history of uncontrolled diabetes mellitus. The surgical tracheostomy was uneventful. Eight days later, she had sudden onset of slow bleed from the tracheostomy site. Local exploration with tube in situ was unremarkable. Heparin thromboprophylaxis was withheld temporarily and tracheal suctioning frequency was reduced. The following day, she developed an acute massive hemorrhage with spurting flow from the tracheostoma, with an estimated blood loss of $>500 \mathrm{~mL}$ in few minutes. Tachycardia was noted, though the blood pressure remained stable.

Acute management was initiated by the neurointensivist with suction for airway clearance and inflation of the tracheostomy cuff to a pressure of $80 \mathrm{~cm} \mathrm{H}_{2} \mathrm{O}$. Fluid resuscitation was initiated along with transfusion of blood and blood products. Direct inspection of stoma by endorhinolaryngologists revealed frank arterial spurt. It was noted that the bleeding point was above the cuff; and for the next 5 minutes, the surgeons tried in vain to contain the bleeder. Immediately endovascular management was resorted to and the patient was transferred to cath lab to visualize and embolize the culprit vessel. Direct pressure was applied on the tracheal and paratracheal soft tissues, with which the bleeding was temporarily controlled. $\overline{1,2,4,5 \text { Department of Neurological Sciences, Christian Medical College, }}$ Vellore, Tamil Nadu, India

${ }^{3}$ Department of Radiology, Christian Medical College, Vellore, Tamil Nadu, India

Corresponding Author: Manju Mary Joseph, Department of Neurological Sciences, Christian Medical College, Vellore, Tamil Nadu, India, Phone: +91 9497392259, e-mail: manjumaryrose2012@gmail.com How to cite this article: Joseph MM, Benjamin R, Padmanabhan A, Bal D, Nair S. Successful Management of a Life-threatening Endotracheal Bleed with Angiographic Stenting. Indian J Crit Care Med 2020;24(3):210-211. Source of support: Nil

Conflict of interest: None

The digital subtraction angiography undertaken within 15 minutes of bleeding revealed a pseudoaneurysm arising from the right innominate artery, in contact with the anterior wall of the tracheostomy tube, which was later confirmed by three-dimensional reconstruction of computed tomography (CT) angiogram (Fig. 1). An endovascular stent implantation was performed, traversing and occluding the mouth of the pseudoaneurysm (Fig. 2). In the process, the right subclavian artery was sacrificed. The patient was sedated, paralyzed, ventilated, and resuscitated with colloids and three packed red cell units. She was transferred back to intensive care unit and her further recovery was unremarkable.

\section{Discussion}

Endotracheal bleed usually happens if the tracheostomy is low and was thought to be invariably fatal. ${ }^{4}$ Due to anatomy of the brachiocephalic artery, it runs a risk of pressure necrosis and erosion from a low lying tracheostomy. Low tracheostomy may result in pounding of the vessel against the inferior edge of the tracheostomy tube leading to erosion of the vessel. Hence, tracheostomy should not be performed lower than the third tracheal ring. ${ }^{5}$ The mechanism of erosion involves both direct pressure and indirect pressure exerted by the tracheostomy tube. Indirect pressure is exerted by the tip of the tube abutting against the anterior tracheal wall, and direct pressure results when the tube rubs on an adjacent vessel. Additional factors responsible for the development of a tracheoarterial fistula are the piston-like movement of a tracheostomy tube connected

(c) The Author(s). 2020 Open Access This article is distributed under the terms of the Creative Commons Attribution 4.0 International License (https://creativecommons. org/licenses/by-nc/4.0/), which permits unrestricted use, distribution, and non-commercial reproduction in any medium, provided you give appropriate credit to the original author(s) and the source, provide a link to the Creative Commons license, and indicate if changes were made. The Creative Commons Public Domain Dedication waiver (http://creativecommons.org/publicdomain/zero/1.0/) applies to the data made available in this article, unless otherwise stated. 


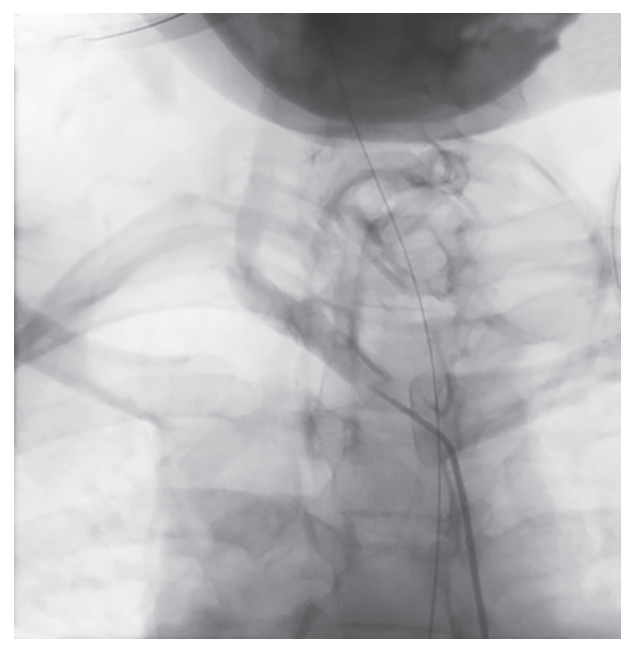

Fig. 1: Pseudoaneurysm corresponding to the margin of the tracheostomy tube

to a ventilator, the use of excessive and continuous cuff pressure, infection around the tracheostomy stoma, and malignant neoplastic invasion of a vessel near the trachea. ${ }^{5}$

The surgical treatment of pseudoaneurysmal erosion involves temporary control of severe hemorrhage while simultaneously maintaining an adequate airway. Many authors recommend hyperinflation of the tracheostomy cuff to tamponade the bleeding vessel as an emergency measure before exploring the site. We feel hyperinflation not only buys time for an emergency exploration but also prevents aspiration of blood and can avoid the "can't ventilate" situation. In our case, the aspiration was prevented with this basic step.

Although surgical interventions are the current mainstay approach for treatment of torrential hemorrhage in a tracheostoma, endovascular occlusive balloons or stent grafts ${ }^{6,7}$ for placement during arteriography have provided another treatment option for such life-threatening bleeding. Endovascular repair is less invasive than open surgery, and usually has a shorter recovery period. Our patient was successfully treated by endovascular stent implantation. A recent case of fatal tracheocarotid artery fistula bleeding was also reported to have been successfully treated by endovascular stent implantation. ${ }^{8}$ We recommend that clinicians be aware of these options while facing uncontrolled tracheostomy bleeding.

We suggest simultaneous multimodal approach toward controlling the hemorrhage surgically or endoscopically, preventing aspiration and hemodynamic resuscitation. Expert management of all these modalities together helped our patient survive the catastrophe.

\section{Conclusion}

Deliberate hyperinflation of the cuff can tamponade the bleeding vessel. The tracheostomy tube should not be removed as this

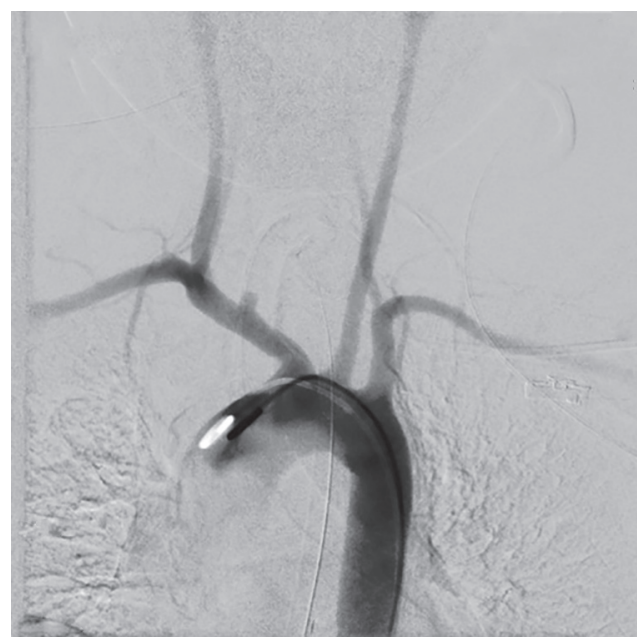

Fig. 2: Pseudoaneurysm from the trunk of the right brachiocephalic artery in aortic arch angiography

may cause aspiration and drowning in blood, as would changing to an oral or nasal endotracheal tube. Immediate interventional radiological procedures such as embolization or endovascular stent implantation are preferable over surgical exploration in a tertiary care setting.

\section{References}

1. Korte W. Uber einige seltenere Nachkrankheiten nach der Tracheotomie wegen Diphteritis. Arch Klin Chir 1879;24:238.

2. Brantigan CO. Delayed major vessel hemorrhage following tracheostomy. J Trauma 1973;13(3):235-237. DOI: 10.1097/00005373197303000-00009.

3. Scalise P, Prunk SR, Healy D, Votto J. The incidence of tracheoarterial fistula in patients with chronic tracheostomy tubes: a retrospective study of 544 patients in a long-term care facility. Chest 2005;128(6):3906-3909. DOI: 10.1378/chest.128.6.3906.

4. Lu KT, Yang SE, Ting MC. Tracheo-innominate artery fistula after tracheostomy - a case report. Acta Anaesthesiol Taiwan 2005;43(4):237-245.

5. Nunn DB, Sanchez-Salazar AA, McCullagh JM, Renard A. Tracheainnominate artery fistula following tracheostomy. Successful repair using an innominate vein graft. Ann Thorac Surg 1975;20(6):698-702. DOI: 10.1016/S0003-4975(10)65764-5.

6. Vaidya N, Strauchler D, Guelfguat M. Computed tomography angiography diagnosis of tracheo-innominate fistula: a case report and review of literature. Quant Imaging Med Surg 2013;3(2):121-125. DOI: 10.3978/j.issn.2223-4292.2013.03.04.

7. Hamaguchi S, Nakajima Y. Two cases of tracheoinnominate artery fistula following tracheostomy treated successfully by endovascular embolization of the innominate artery. J Vasc Surg 2012;55(2): 545-547. DOI: 10.1016/j.jvs.2011.08.006.

8. Hsu Y-C, Huang Y-C, Hsu C-W. Tracheo-carotid artery fistula: an unusual cause of tracheostomy bleeding. QJM 2016;109(3):209-210. DOI: 10.1093/qjmed/hcv210. 